\title{
Lymphocyte subpopulations at the onset of Type 1 (insulin-dependent) diabetes
}

\author{
J. Ilonen, H.-M.Surcel, A. Mustonen, M.-L. Käär and H. K. Åkerblom \\ National Public Health Institute, Oulu, Department of Pediatrics, University of Oulu, Oulu, and the Children's Hospital, University of Helsinki, \\ Helsinki, Finland
}

\begin{abstract}
Summary. Percentages of various T-lymphocyte subpopulations in the blood were studied at the onset of Type 1 (insulindependent) diabetes. The number of lymphocytes with OKT8 markers was higher in the diabetic patients than in control subjects $(p<0.005)$ and the ratio between helper and suppressor/cytotoxic T-cells (OKT4/OKT8 ratio) was lower in the diabetic patients than in the control group $(p<0.005)$. The values in the diabetic patients were, however, essentially within the normal range. When Ia-antigen-positive cells were analysed in T-cell-enriched cell populations, Type 1 diabetic patients had higher percentages of these cells $(p<0.01)$, suggesting T-cell activation. When patients with either of the two
\end{abstract}

major HLA risk antigens (Dw3 or Dw4) were compared, there was a significant difference in the OKT4/OKT8 ratio $(p<$ 0.005), as Dw3-positive patients had higher and Dw4-positive patients lower ratios. This finding supports the concept of heterogeneity of the disease and can also explain the discrepant findings of earlier studies. When patients with complementfixing islet cell antibodies were compared with patients without islet cell antibodies, there was no significant difference, although the OKT4/OKT8 ratio was slightly lower in the complement-fixing islet cell antibody-positive patients.

Key words: Type 1 diabetes, T-lymphocytes, heterogeneity.
The aetiology of Type 1 diabetes is unclear, but there is strong evidence for the role of autoimmune mechanisms as well as of viral infections. Most probably there is heterogeneity within the disease as also suggested by HLA studies, but a combined form involving both infectious and autoimmune mechanisms may actually be most common [1]. In the present study we analysed relations between lymphocyte subpopulations which have been found to be abnormal in certain infections, autoimmune states and situations where an abnormal immune regulation has been found [2].

\section{Subjects and methods}

\section{Patients}

Sixty-three patients (mean \pm SD age $8.1 \pm 4.1$ years) with Type 1 diabetes were included in the study. They were all studied within 1 week from diagnosis of the disease.

\section{Preparation of lymphocytes and T-lymphocyte-enriched cells}

Mononuclear cells were isolated from heparinized peripheral blood by Lymphoprep gradient centrifugation, washed three times with Hank's balanced salt solution and suspended in RPMI-1640 tissue culture medium containing $10 \%$ fetal calf serum. Lymphocytes were then depleted from adherent cells by incubation in plastic Petri dishes at $37^{\circ} \mathrm{C}$ for $30 \mathrm{~min}$ in a $5 \% \mathrm{CO}_{2}$ atmosphere. Lymphocytes were further enriched for T-cells using 2-aminoethylisothiouroniumbromide hydrobromide(AET)-treated sheep red blood cells.

\section{Lymphocyte subpopulations}

A modified indirect immunofluorescence method [3] was used to determine the percentage of cells with each of the markers defined by the following monoclonal antibodies: OKT3, OKT4, OKT8 and OKIa1 (Ortho Diagnostics, Raritan, New Jersey, USA). The percentage of positive cells was determined by counting 200 cells with light microscopy and fluorescence illumination alternately.

\section{HLA-typing}

HLA-A, -B and -C antigens were determined with a standard twostage microlymphocytotoxicity test. HLA-D typing was carried out with local homozygous typing cells as described previously [4].
Control subjects were healthy children and children admitted to hospital for minor surgical procedures (mean $\pm S D$ age $10.0 \pm 4.1$ years). In all cases blood specimens for the study were taken pre-operatively together with routine blood tests. 
Table 1. Median percentages of lymphocytes with different surface markers in children with Type 1 diabetes of recent onset and in control subjets

\begin{tabular}{llllll}
\hline \multicolumn{5}{c}{ Lymphocytes (\%) } \\
\cline { 2 - 6 } & OKT3 & OKT4 & OKT8 & OKT4/8 & OKTa1 \\
\hline $\begin{array}{c}\text { Type 1 diabetic } \\
\text { children }(n=45)\end{array}$ & 73.0 & 43.5 & 25.5 & 1.6 & $\begin{array}{l}11.5 \\
(n=37)\end{array}$ \\
$\begin{array}{c}\text { Normal children } \\
(n=31)\end{array}$ & 74.5 & 47.5 & 21.0 & 2.3 & $\begin{array}{l}10.8 \\
(n=26)\end{array}$ \\
\hline
\end{tabular}

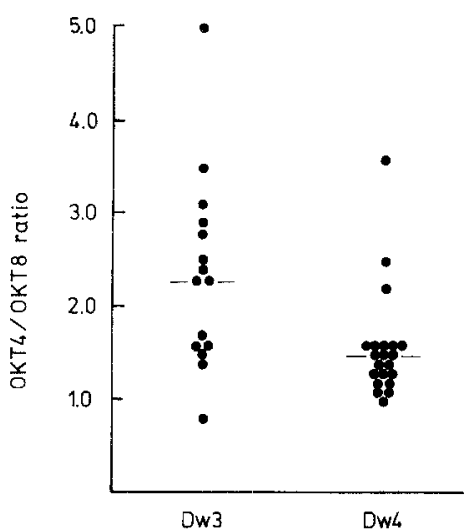

Fig. 1. The ratio between helper and suppressor cytotoxic T-cells (OKT4/OKT8 ratio) in Type 1 diabetic patients with either HLA-Dw3 or HLA-Dw4 as a disease risk antigen

\section{Measurement of islet cell antibodies (ICA)}

ICA were determined by both conventional indirect immunofluorescence and the complement-fixation method as described previously [5].

\section{Statistics}

The Mann-Whitney U-test was used for analysis of differences between groups.

\section{Results}

In the first phase of the study, lymphocyte subpopulation analyses were carried out on peripheral blood mononuclear cells depleted of adherent cells (Table 1). The percentage of OKT8-positive cells was higher $(p<$ $0.005)$ and the OKT4/OKT8 ratio lower $(p<0.005)$ in the Type 1 diabetic patients than in the control subjects. However, the values in the diabetic patients were essentially within the normal range.

In the second phase the lymphocyte subsets were studied in AET-treated sheep-red-blood-cell-enriched T-cell populations to obtain information on T-cell activation. In this smaller group of 18 Type 1 diabetic patients the median percentage of OKIa1-positive cells was 5.0 (range 1.0-20.0), significantly higher $(p<0.01)$ than in 13 control subjects (median 2.0, range $0.5-8.5$ ), indicating the presence of activated $\mathrm{T}$ cells in the blood of patients with recent-onset Type 1 diabetes.

On the basis of HLA typing results, the patients were divided into groups with different HLA risk antigens. There were seven patients with the combination Dw3/Dw4, 15 with Dw3/x and 21 with Dw4/x, where $\mathrm{x}$ means any other $\mathrm{D}$ antigen or possible homozygosity. Fifteen of the 58 HLA-typed patients did not have any of these risk antigens. Because there was no difference between the OKT4/OKT8 ratio calculated from total lymphocytes or enriched $\mathrm{T}$ cells in either patients or control subjects, the ratio values were combined for comparison of patients with different HLA types (Fig. 1). The median OKT4/OKT8 was 2.3 when calculated for all Type 1 diabetic patients with Dw3/x. This is higher $(p<0.005)$ than the median value of 1.5 for Type 1 diabetic children with Dw4/x, and higher than the value 1.3 for patients with Dw3/Dw4.

ICA were found at the onset of the disease in 46 of the 61 patients in whom their presence could be determined; in 39 cases the antibodies were also complement fixing. The median OKT4/OKT8 ratio of 1.6 for ICA complement-fixation-positive patients is slightly lower than the ratio 1.8 for ICA-negative patients, but the difference is not significant.

\section{Discussion}

The results of the present study showed a trend towards a decreased ratio between helper and suppressor $T$ cells at onset of Type 1 diabetes, which is in accordance with some earlier findings $[6,7]$, but contradicts others $[8,9]$.

One of the central problems in the study of the pathogenesis of Type 1 diabetes may be the heterogeneity of the disease. This heterogeneity can also explain differences and discrepancies between the results of various groups, as patient material and thus also the proportions of cases with various disease mechanisms may be different.

The association of the disease with two major HLA risk antigens, DR3 and DR4, is one of the findings also suggesting pathogenetic heterogeneity. DR3 is an antigen associated with a group of diseases where autoimmune phenomena are central, and the pathogenesis of the DR3-associated form Type 1 diabetes has also been suggested to be dominated by an autoimmune process, whereas in DR4-positive cases viral infections or other environmental factors could have a more direct damaging effect [10].

The findings of the present study strongly support the concept of heterogeneity in Type 1 diabetes. The decreased OKT4/OKT8 ratio found in Type 1 diabetic patients was even more pronounced in patients with Dw4, who dominated our patient series. Dw3-positive patients had a significantly higher helper/suppressor ratio, and it is possible that this form of disease has dominated some other studies. The patients of the pre- 
sent study were all children; the 'autoimmune' form of the disease is likely to be more common in patients with the onset of Type 1 diabetes in adulthood. However, although a decreased helper/suppressor T-cell ratio and increased percentage of cells with OKT8 marker were found among diabetic patients, it has to be noted that the individual values of Type 1 diabetic children were essentially close to the normal range (Table 1).

The signs of lymphocyte activation were sought by counting $T$ cells with Ia-antigen. An increase in activated $T$ cells was found, supporting the reports of Jackson et al. [11] and Pozzilli et al. [7], although the mean number of activated $T$ cells was relatively low.

Acknowledgements. The study was supported by Hoechst Fennica Research Foundation and Foundation for Diabetes Research.

\section{References}

1. Irvine WJ (1977) Classification of idiopathic diabetes. Lancet 1: 638-642

2. Reinherz EL, Schlossman SF (1980) The differentiation and function of human T lymphocytes. Cell 19:821-827

3. Kung PC, Goldstein G, Reinherz EL, Schlossman SF (1979) Monoclonal antibodies defining distinctive human T-cell antigens. Science 206: 347-349

4. Ilonen J, Lagerstedt A, Koskimies S, Reunanen M (1983) HLADwl and BfF as protective markers in multiple sclerosis. J Neuroimmunol 5:283-288
5. Mustonen A, Knip M, Åkerblom HK (1983) An association between complement-fixing cytoplasmic islet cell antibodies and endogenous insulin secretion in children with insulin-dependent diabetes mellitus. Diabetes 32: 743-747

6. Mascart-Lemone F, Delespesse G, Dorchy H, Lemiere B, Servais $\mathrm{G}$ (1982) Characterization of immunoregulatory $\mathrm{T}$ lymphocytes in insulin-dependent diabetic children by means of monoclonal antibodies. Clin Exp Immunol 47: 296-300

7. Pozzilli P, Zuccarini O, Iavicoli M, Andreani D, Sensi M, Spencer KM, Bottazzo GF, Beverley PCL, Kyner JL, Cudworth AG (1983) Monoclonal antibodies defining abnormalities of $\mathrm{T}$ lymphocytes in Type I (insulin-dependent) diabetes. Diabetes 32: 91-94

8. Buschard K, Ropke C, Madsbad S, Mehlsen J, Rygaard J (1983) T lymphocyte subsets in patients with newly diagnosed Type I (insulin-dependent) diabetes: a prospective study. Diabetologia 25: $247 / 25 / x$

9. Galluzzo A, Giordano C, Sparacino G, Rubino G, Camarda C, Bompiani GD (1982) Suppressor T-cell deficiency in Type I (insulin-dependent) diabetes mellitus investigated with monoclonal antibodies. Diabetologia 23: 168 (Abstract)

10. Rotter JI, Rimoin DL (1978) Heterogencity in diabetes mellitus update 1978: evidence for further genetic heterogeneity within juvenile onset insulin dependent diabetes mellitus. Diabetes 27 : $599-608$

11. Jackson RA, Morris MA, Haynes BF, Eisenbarth GS (1982) Increased circulating Ia-antigen-bearing $\mathrm{T}$ cells in Type $\mathrm{I}$ diabetes mellitus. N Engl J Med 306: 785-788

Dr. J. Ilonen

National Public Health Institute

PL 310

SF-90101 Oulu 10

Finland 